\title{
Digital Leadership in Managing Employee Work Motivation (Case Study: Oil and Gas Industry in Indonesia)
}

\author{
Fatimah Malini Lubis ${ }^{1}$, Zahara Tussoleha Rony ${ }^{2}$, Budi Santoso ${ }^{3}$ \\ \{lubisfm@gmail.com ${ }^{1}$, zahara.tussoleha@dsn.ubharajaya.ac.id², budi.bodjong@gmail.com ${ }^{3}$ \} \\ LP3I Jakarta, Indonesia ${ }^{1}$ \\ Universitas Bhayangkara Jakarta Raya, Indonesia ${ }^{2}$ \\ Akademi Angkatan Udara Yogyakarta, Indonesia ${ }^{3}$
}

\begin{abstract}
In recent years the world oil price has experienced a very significant shock and had become the worst history in the oil and gas industry. As a result of the uncertainty in the oil price, the role of the leadership is very important in maintaining employee motivation. Digital leadership is one of the leadership styles that a leader must possess in anticipating the current uncertainty in oil prices. Researchers interviewed employees in several oil and gas companies in Indonesia. This study used a qualitative case study with snowball and purposive sampling approach. Novelty of this research is to describe how the digital leadership in maintaining work motivation. The results showed that digital leadership was one of the leadership styles that could maintain the work motivation of oil and gas employees in an unpredictable oil price condition through 3 (three) factors such as uncertainty condition, innovation and adaptability.
\end{abstract}

Keywords: Digital Leadership, Work Motivation, Oil and Gas Industry.

\section{Introduction}

Indonesia's high economic growth in the past 10 years has made this country with a population of approximately 280 million people worthy of being considered economically in the Southeast Asia region and in the world especially with its active participation in the world G-20 organization. Outside tax revenue, according to the state revenue and expenditure budget 2018 , Oil and gas contribute $90 \%$ of state revenues and high consumption levels contribute to very significant economic growth rates. The situation of the world oil and gas market which is currently uncertain on a macro impact on state revenues through exports and directly affects the microeconomic conditions in the country; the country's main industries which are the mainstay of increasing Gross Domestic Gross Rate (GDP) are slowly becoming unattractive in the eyes of the actors both organizations and individuals, very different from the situation in the early 1980s which made the oil and gas industry and banking as the main career choices workforce at that time. This phenomenon is a widespread discussion and debate within the country along with the rapid growth of the digital industry which is the strategic mainstay of the millennial youth; the fact that new trends towards the reluctance of millennial youth to work in the real sector will threaten the country's macroeconomic conditions.

Various irrefutable evidence of the importance of human resources for the success of an organization or industry has been tested during this century in the form of scientific research 
that has been developed in various parts of the world, and now Indonesia's mainstay and strategic industries are experiencing degradation in quality and quantity of personnel that need improvement and individual development of actors from several aspects which are important indicators of specialization including motivation. Motivation of someone who is a member of an organization can be encouraged and developed by a leader in the form of implementing an effective leadership; various literature on the relationship between leadership and employee motivation or vice versa have proven that both have a linear relationship. This study presents an empirical study with qualitative methods to obtain a new format of the relationship between leadership and employee motivation in an effort to encourage human resources active in the Indonesian oil and gas industry to be able to provide works and contribute positively to the maximum in carrying out their work.

\section{Literature Review}

Motivation is a subject of great interest to scholars in different areas, including psychology, sociology and education [1] Intrinsic motivation refers to behavior that is driven by internal rewards. Motivation that initiates and sustains behaviour is one of the most significant components of learning in any environment [2]. Several models shape the educational concept of socio-cultural differences on formation of motivation and foreign language motivation in particular. Leaders know that at the heart of every productive and successful business lies a thriving organizational culture and hardworking people collaborate passionately to produce great results [3]. Robbins in Sentot Imam Wahyono argues that motivation is the willingness to issue a high level of effort for organizational goals that is conditioned by the ability of that effort to meet some individual needs [4]. This means that someone needs to strive with maximum effort in achieving its goals that will contribute to the organization. Chandra Sekhar et.al (2013) said motivation to work as a support person to provide work to the organization to be able to improve individual and organizational performance even in a better way than they usually do [5]. Vuori and Okkonen stated that motivation can be useful for providing knowledge through an intra-organizational social media platform to help the organization to achieve its goals [6].

Dubrin in Zahara said leadership is the ability to inspire and support among people in need to achieve organizational goals [7]. Challenges for digital leadership based on Reddy, Pulla define as, (1) digital transformation and company culture: the domain of work culture is usually where the biggest amount of rejection or adoption happens in the face of new technologies. Therefore, it is dire need for cross- generational communication and company culture, (2) digital transformation and generation change: right now, generation $\mathrm{z}$ is entering into the workforce in growing numbers. These intelligent and tech- savvy young digital natives have been raised democratically and work most effectively when encouraged to contribute to company processes with their unique experiences, (3) digital transformation and HR Management: In this process, the manager required to attain two new competencies: media competency and intellectual competency, (4) digital transformation and marketing \& sales: New products and services as well as the enormous opportunities of big data and social media make abundantly clear how much marketing and sales profit from digitalization, and this is especially true in communication sector, (5) digital transformation and communication: the boom in social media especially leads to new challenges and opportunities in all sectors of internal as well as external corporate communication, (6) digital transformation and the organization: It mainly depends on two things- how each unit should act to complete the tasks at hand and how each business unit should 
synchronize with all others [8]. Digital leadership is essential to the success of any digital transformation and requires a focus on customer engagement, the need for advanced technical tools and a high capacity for storage, and a framing of the culture to support digitization in different forms [9]. Gupta operationalizes uncertainty avoidance as being the measure of tolerance for ambiguity [10]. In contrast, Endres and colleagues explore tolerance for ambiguity as its own construct and make no mention of its relationship to uncertainty avoidance [11]. This pattern can be seen throughout the literature surrounding uncertainty avoidance and tolerance for ambiguity. The study of digital leadership is the part of the study about leadership based upon the upper echelon theory developed by Hambrick and Mason [12], where the yield of association is impacted by the pioneer choice dependent on the translation and psychological from the entertainers. As far as the advanced authority, the idea is made by joining the administration expertise and the computerized ability to upgrade the advantage of computerized innovation so as to in-wrinkle the business execution. Rudito characterizes the attributes of advanced administration comprises of innovation initiative, computerized visioning and computerized execution [13]. Pearl Zhu characterizes the criteria of computerized initiative comprise of 5 qualities: (1) thought pioneer, since the challenge become tight and hyper because of new contender coming that upset the occupant business, consequently it requires the pioneer who has extreme capacity. (2) inventive pioneer, computerized innovation brings new plan of action and give borderless effect to the advancement. Advancement become the key of upper hand, henceforth the computerized pioneer must have innovativeness and development attitude that could figure the possibility of things to come into truth of business (3) Global Visionary Leader, an advanced pioneer can give guidance and to turn into a symphony in changing the computerized business change. (4) Inquisitive Leader, with the intricate and dynamic biological system due to VUCA factors, the computerized pioneer hast to have the learning ability and has the capacity to executing the learning and advanced ability. (5) Profound Leader, the advanced pioneer has the information and comprehend top to bottom as far as strategy since in web and computerized period, the data is getting open and everyone has the ability to get to and examine data thoroughly, by utilizing their understanding, supposition and combining the data could significant the information to take the basic leadership [14]. Sandel characterize the advanced initiative as the abilities and limits that could give the imagination condition by upgrading the innovation and computerized capacity [15]. The advanced trademark is the inventiveness head, rousing pioneer, validity pioneer, more extensive information pioneer, shared and intuitive pioneer and trust the subordinates.

Innovativeness is an individual's capacity to tackle issues, holes in information with an assortment of arrangements and produces an item that is new and helpful or has esteem. Inventiveness is the capacity to produce new thoughts into reality through different reasoning or carry numerous answers for take care of an issue [16]. Inventiveness is characterized as the way toward getting touchy to issues, inadequacies, holes in information, missing components, disharmony and others [17]. The word inventiveness originates from the Latin is creo which in English is "to make, make" [18]. Imagination alludes to the wonder when an individual makes something new (an item, an answer, and masterpieces) that has a worth. Imagination measurements are: (1) familiarity is the capacity to produce thoughts; (2) the adaptability of having the option to see the inquiries or subjects from an assortment of viewpoints; and (3) innovation or realness is the embodiment of inventiveness. Different elements of imagination are, the components of the individual, procedure, item, and press [19]. The primary inventive measurement is Person. An inventive has a character that is essentially not the same as the individuals who are less innovative. Phases of the procedure of imaginative speculation by Wallas comprise of four stages: (1) readiness, (2) Incubation, (3) Illumination, and (4) check 
[20]. Amabile has contended that an innovative item or an individual's reaction is said to be inventive if in the judgment of the specialists who have expert in the field said that it was imaginative [21]. An item evaluated inventive in the event that it is new, interesting, valuable, genuine, is worth as far as explicit needs, shows the strategy they have never or once in a while done by the past individual. The fourth measurement is the Press; nature is one of the components that impact innovativeness.

Vulnerability hints in ordinary language in three distinct ways, identifying with the outer world, to information, and to the psyche, separately. We may state that the result of a soccer coordinate, or a political decision, or a salvage activity is questionable, implying that the (future) situation in the outside world isn't fixed or decided. We may state that there is impressive vulnerability in a climate conjecture, in a fish stock evaluation, or in an atomic model. Right now, "vulnerability" ordinarily isn't thought to dwell on the planet itself, yet in the blemished nature of our insight about that world: There is a determinate biomass of the fish stock, it is only that we don't have the foggiest idea about this number. Finally, a common usage of "uncertainty" and "uncertain" (in particular in Norwegian, with "usikkerhet" and "usikker") is the one that relates to our mind and our emotions, intentions and actions. Hence, we may say that we are uncertain about what to do or feel "usikker" - insecure in English, but also unsure, perhaps bordering to feeling anxious, afraid or helpless. These three dimensions of the everyday notion of uncertainty are often, but not always, interconnected. In what follows, we shall leave the dimension of the mind and narrow the discussion to the concept of scientific uncertainty; however, although often claimed to be definable in terms of imperfection of knowledge, not even this concept avoids the entanglement of properties of the world (i.e., how the world is, was or will be) with properties of knowledge (i.e., what we can determine about the status of the world). There are clear cases of uncertain estimates of determinate entities, such as the current fish stock of, say, cod. The vulnerability in an anticipated worth, in any case, may be because of the unfixed direction of the world, or because of flawed headway of science, or both. Furthermore, critically, we will most likely be unable to tell. Walker recognizes this situation and characterizes logical vulnerability as "any departure from the unachievable ideal of complete determinism" [22]. Historically, the focus of uncertainty analysis has been on the quantifiable aspects. One of the most conventional and widespread distinctions used in categorizing scientific uncertainties is that between uncertainty and [23]. Information vulnerability (Type I vulnerability) - emerging from absence of logical information about explicit components, parameters or models that can halfway be diminished through further examination. This incorporates parameter, model and situation vulnerabilities. It very well may be communicated by the questionable conviction about the probability of the variable (irregular variable) having various qualities spoken to by likelihood dissemination. Fluctuation (Type II vulnerability) - emerging from normal inconstancy because of genuine heterogeneity that isn't generally diminished through further investigation. Inconstancy is described by recurrence dissemination (discrete irregular variable) or through a likelihood thickness work. This incorporates genuine contrasts that happen between various situations or people. While this differentiation is a valuable hypothetical build, it can frequently be hard to make by and by; parameters will regularly be related with information vulnerability - because of confinements of estimations and models - and natural changeability. See for instance the diagram of model vulnerabilities introduced in Figure 1. An increasingly principal issue is that, much of the time, vulnerability investigation is joined by an understood supposition that the vulnerability can be evaluated and communicated as a blunder, that the amount includes a focal incentive inside a perceptible range, and that the frameworks being depicted are constrained. In this manner, vulnerabilities can be spoken to utilizing insights by appointing straightforward standard 
deviations or likelihood conveyances to the parameters and the information. While it ought to be valued that changeability in model info parameters can be an authentic part in the vulnerability in yields. Later work has concentrated on more extensive (for the most part less quantifiable) parts of vulnerability - especially identified with utilizing unsure data in basic leadership and in imparting vulnerabilities.

\section{Methodology}

This research is a qualitative case study research approach, which conducted learn a real case context phenomenon in the oil and gas industry at Indonesia. The method and procedure employed in this study is case study research design by Yin, with the stages are: (1) research questions; before making a series of questions, the researcher began by conducting a literature review by reading journals related to performance motivation, digital leadership, creativity and organizational. This interview guide was used by researchers when interviewing informants, (2) research theorem or theoretical framework (proportion of studies); Researchers study, collect, and analyze of data related, (3) unit identification analysis; the next stage, the researcher made preliminary observations with government officials. To add some accurate information and more than one source, researchers also conducted observations in the government office and talked with informants. In addition of a party and the affected by organizational changes was observed, researchers also observed the real situation. This is done to get the results of observations, their experiences and opinions on organizational changes that occur. The results of information and discussions with various internal parties become the data, hence will be a multi-source document for researchers. To get direction and sharpness on these problems, researchers conducted discussions with human resource practitioners who had conducted research with case studies, (4) The logical relations of data with theorem or theoretical (logical relation); The researcher made a research proposition and set out the analysis units from the start which had been chosen by the researcher as a case study. Then, the researcher also assembled the logic by the research question, proposition, and analysis units. Propositions were necessary to identify the relevant information related to the problems of employee's performance motivation of post organization changes. If the researcher did not make a proposition, the researcher would be easily tempted to collect everything that was not needed. At this stage, the researcher made the questions point to the case of de-motivation of employees beginning with giving an overview related to employee motivation prior and post organization changes in order to provide answers to what causes demotivation of employees, how committed they are within organization and how to foster their performance motivation of post organization changes, (5) Criteria to interpret the findings; the researcher conducted the data collection and analysis. In this activity, researchers prepare time, mentally and practice skills to foster good relations with related parties and improve the ability to obtain information through the interview process [24]. This interview process requires skills to listen, ask questions, read the body language of the informants and conclude the results of interviews.

\section{Result and Findings}

Based on the results of interviews conducted by researchers, the following are the results of the informant's expression most employees revealed that one of the conditions of the 
uncertainty condition was fluctuating oil prices. This had an impact on the demands of the company to make frequent changes. Some revealed that the frequent changes caused employees to not know the purpose of the direction given by their superiors. Thus, this factor causes demotivation of employee work because they are not ready to deal with changes in a fairly frequent period of time. Another condition expressed by employees is that the oil and gas industry is not a high work profile anymore in the workforce, but they revealed that in the current uncertainty condition, it is very difficult to change jobs from one company to another. This is very different while oil prices are at a peak and stable where employees can easily move to get very attractive financial offers. This has caused a turnover phenomenon that is quite a concern in all oil and gas companies. Therefore, this condition requires the attitude of a leader who is able to adapt to the demands of a very fast and unavoidable digital era. Digital leadership has become a leadership style that can answer the challenges faced by companies. What can be done by responding to this situation is be digitally intentional; become a digital leader, define your digital strategy; assess your firms digital readiness; take stock of your digital investments; prioritize when change is needed most; invest a landmark profit; foster a strong digital culture; set a common digital language; prepare your people and be agile in your focus.

The informant also stated that in an uncertain situation in the oil and gas industry not only gave them a higher workload but on the other hand it made informants like the challenge that emerged as the attitude of the company to its employees to foster a culture of innovation in all fields and demand all employees to be creative and to make efficiency in accordance with the fields they control. This will be a stimulus to bring innovation from employees by seeing a condition out of the box. Innovation will generate creativity on all fronts in achieving efficiency and productivity in terms of work and improving employee performance that supports the company's objectives in the uncertainty condition. To support this innovation, the leadership role is needed to create a conductive atmosphere in the work environment. Digital leadership will be able to give enthusiasm to innovate to employees and not hesitate to make changes in the near future. Digital leaders are very open to input and creative ideas that produce new things and of course will be an intake for employee motivation. Digital leaders will be able to attract employee creativity as a very important skill for employees at this time. Employees in the future will require all employees to have high creativity in order to maintain the company in the midst of very heavy market competition. Anna Jordanous provides a method for measuring machine creativity [25]. However, Jordanous' outcomes are generalizable to people also, though Ritchie's proposed criteria were definitely not. Jordanous endeavored to distinguish various segments of imagination by dissecting an enormous number of logical writings. All the more significantly, by utilizing the strategy for content investigation, the segments were built up in a goal way. From one viewpoint, there was a corpus of articles that needed to do, somehow, with inventiveness in hardware. Mixes, for example, 'computational imagination' and 'inventive framework', among others, were utilized to choose writings for the corpus of inventiveness articles. Then again, there was a corpus of writings which had nothing to do with innovativeness. By looking at the two corpora, Jordanous broke down which words showed up more frequently in writings about innovativeness than they did in writings on inconsequential subjects. By then gathering the subsequent words, Jordanous deciphered the 18 formulae proposed by Ritchie into 14 segments of imagination. 


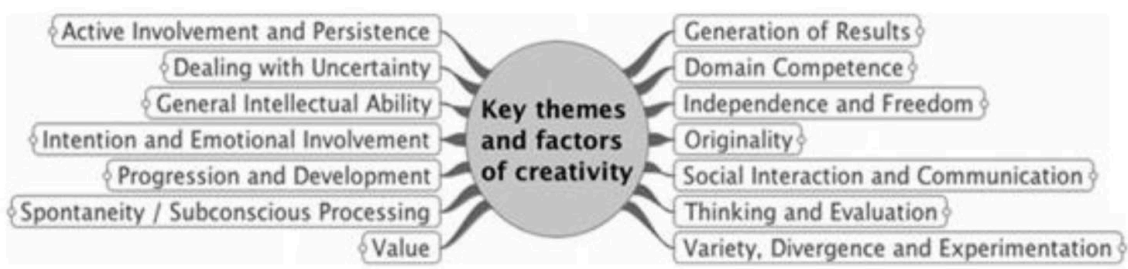

Fig. 1. Fourteen Components of Creativity (Jordanous, 2012).

To deal with uncertainty conditions, the ability to adapt to the environment and something new is needed. Today most companies will have a population of 3 generations. For informants who are included in the $\mathrm{X}$ generation, expressing very rapid changes will be difficult to follow and unable to keep up with work requirements with their ability to work. So that this causes the informants who are included in generation $X$ to be motivated and feel eliminated by the existence of natural selection from rapid change itself. For informants belonging to the $\mathrm{Y}$ generation, there are new challenges that are quite interesting to follow up. The monotonous work atmosphere will provide saturation for generation $\mathrm{Y}$ in doing work only to fulfill their obligations as employees without excessive demands from the company. If it is sustainable, this will bring employees down motivation and have no long-term goals in their career. Informants who entered the $\mathrm{Z}$ generation preferred things that were fast and all digital. With market conditions demanding rapid change, generation $\mathrm{Z}$ informants do not make it a problem, but can increase work motivation and make the world of work. To deal with various types of this generation, the role of digital leaders is very much needed. With rapid adaptability to adjust what needs to be done to prepare employees who are ready to face changing times. Digital leaders are expected to be responsive and synergize with their environment both internally and externally so that employees can have high work motivation and be supported by their leaders. As Baker and Carson explored the use of attachment and adaptation in mitigating the negative effects of uncertainty avoidance in individuals [26]. They found that those high in uncertainty avoidance were likely to use both attachment and adaptation to overcome feelings of discomfort in uncertain situations. Namely, they "attached" by forming a strong identity with their immediate group, and they "adapted" by adjusting to their surrounding environment.

Many companies faced employees with cross-generation demographics. Current digital age behavior such as the use of social media and storage through the cloud has become a very common thing for employees to do especially in the oil and gas industry. Digital leadership skills are necessary in making organizational change through digital transformation. This is consistent with research conducted by Mouhamadou Sow and Solomon Aborbie who stated leaders must be flexible and support their employees who can make a difference during and after a digital transformation, along with recognizing what they have to offer and how they can make a difference at the organization in the long term [27].

\section{Conclusion}

Uncertainty condition in the oil and gas industry is a challenge for employees, especially in maintaining work motivation. The condition of uncertainty conditions, especially those caused by fluctuations in oil prices, will require the role of leaders in addressing the conditions facing all oil companies in Indonesia. Based on the findings of this study, it shows that 3 (three) 
factors between uncertainty condition, innovation and adaptability are factors that need to be considered by companies in maintaining employee work motivation. Digital leaders with the ability to be able to respond to the rhythm of change are relatively quickly expected to be able to answer the company's challenges in maintaining employee work motivation. Another role of digital leadership is being able to make employees have good adaptability in anticipation of attitudes that are often made by companies in responding to market challenges and maintaining the sustainability of the company.

Acknowledgements. This research provided by personal funding and supported by some people in oil and gas industry in Indonesia. Thank you for ICSS Committee for helpful the publishing of this journal. All citations and reading sources used as a theoretical basis in research have been quoted in accordance with the norms of applicable academic citations.

\section{References}

[1] J. K. Kazakova and E. M. Shastina, "The impact of socio-cultural differences on formation of intrinsic motivation: The case of local and foreign students," Learn. Motiv., vol. 65, pp. 1-9, 2019.

[2] M. Fırat, H. Kılınç, and T. V. Yüzer, "Level of intrinsic motivation of distance education students in e-learning environments," J. Comput. Assist. Learn., vol. 34, no. 1, pp. 63-70, 2018.

[3] G. E. Gignac and B. R. Palmer, "The Genos employee motivation assessment," Ind. Commer. Train., 2011.

[4] S. Imam and W. Wahyono, "Pengaruh Corporate Governance Terhadap Manajemen Laba Pada Perusahaan Jasa di Indonesia (Studi Kasus Pada perusahaan Jasa Yang Terdaftar di Bursa Efek Indonesia Tahun 2005-2007),” J. Akunt. Indones., vol. 1, no. 1, pp. 40-49, 2016.

[5] C. Sekhar, M. Patwardhan, and R. K. Singh, "A literature review on motivation," Glob. Bus. Perspect., vol. 1, no. 4, pp. 471-487, 2013.

[6] G. Schiuma, V. Vuori, and J. Okkonen, "Knowledge sharing motivational factors of using an intra-organizational social media platform," J. Knowl. Manag., 2012.

[7] A. J. DuBrin, Handbook of research on crisis leadership in organizations. Edward Elgar Publishing, 2013.

[8] P. Reddy, "A critical review on leadership in the digital age," Int. J. Acad. Res. Dev., vol. 3, no. 1, pp. 467-468, 2018.

[9] O. A. El Sawy, P. Kræmmergaard, H. Amsinck, and A. L. Vinther, "Building the foundations and enterprise capabilities for digital leadership: The LEGO experience," 2015 Soc. Inf. Manag. Pap. Award. Compet., 2015.

[10] S. F. Gupta, "Integrating national culture measures in the context of business decision making," Cross Cult. Manag. an Int. J., 2012.

[11] M. L. Endres, S. Chowdhury, and M. Milner, "Ambiguity tolerance and accurate assessment of self-efficacy in a complex decision task," J. Manag. Organ., vol. 15, no. 1, pp. 31-46, 2009.

[12] D. C. Hambrick and P. A. Mason, "Upper echelons: The organization as a reflection of its top managers," Acad. Manag. Rev., vol. 9, no. 2, pp. 193-206, 1984.

[13] P. Rudito and M. F. N. Sinaga, Digital Mastery, Membangun Kepemimpinan Digital Untuk Memenangkan Era Disrupsi. Gramedia Pustaka Utama, 2017.

[14] P. Zhu, Digital master: Debunk the myths of enterprise digital maturity. Lulu Press, Inc, 2015.

[15] S. Sandell, Digital Leadership: How Creativity in Buisness Can Propel Your Brand \& Boost Your Results. BookBaby, 2013.

[16] J. P. Guilford, "Fundamental statistics in psychology and education," 1950.

[17] E. P. Torrance, "The Torrance Tests of Creative Thinking-Norms-Technical Manual Research Edition-Verbal Tests," Forms A B-Figural Tests, Forms A B, 1966. 
[18] Anoiko, "Creativity," 2011. [Online]. Available: https://oiko.files.wordpress.com/2011/03/2011.

[19] M. Rhodes, “An analysis of creativity," Phi Delta Kappan, vol. 42, no. 7, pp. 305-310, 1961.

[20] G. Wallas, "The art of thought harcourt," Bruce Company, New York, 1926.

[21] T. M. Amabile, "The social psychology of creativity: A componential conceptualization.," $J$. Pers. Soc. Psychol., vol. 45, no. 2, p. 357, 1983.

[22] W. E. Walker et al., "Defining uncertainty: a conceptual basis for uncertainty management in model-based decision support," Integr. Assess., vol. 4, no. 1, pp. 5-17, 2003.

[23] W. J. Warren-Hicks and D. R. J. Moore, "Uncertainty in ecological risk assessment." SETAC Press Publisher, 1998.

[24] R. K. Yin, "Case study research: design and methods (ed.)," Thousand Oaks, 2003.

[25] A. Jordanous, "A standardised procedure for evaluating creative systems: Computational creativity evaluation based on what it is to be creative," Cognit. Comput., vol. 4, no. 3, pp. 246279, 2012.

[26] D. S. Baker and K. D. Carson, "The two faces of uncertainty avoidance: Attachment and adaptation," J. Behav. Appl. Manag., vol. 12, no. 2, p. 128, 2011.

[27] M. Sow and S. Aborbie, "Impact of leadership on digital transformation," Bus. Econ. Res., vol. 8, no. 3, pp. 139-148, 2018. 